\title{
Correspondence
}

\section{Prevalence of obstructive sleep apnea in children with sickle cell disease at a tertiary hospital in Saudi Arabia}

\section{To the Editor}

I have 3 comments on the interesting study by Al-Otaibi et $\mathrm{al}^{1}$ on the prevalence of obstructive sleep apnea (OSA) in children with sickle cell disease (SCD) in the Kingdom of Saudi Arabia (KSA).

First, based on nocturnal polysomnography (PSG) parameters, Al-Otaibi et al found that the prevalence of OSA in the studied SCD cohort was $80 \%$ using an apnea hypopnea $(\mathrm{AH})$ index cutoff of $\geq 1$ and $7.7 \%$ using $\mathrm{AH}$ index cutoff of $\geq 5 .{ }^{1}$ Apart from few limitations addressed by Al-Otaibi et $\mathrm{al}^{1}{ }^{1} \mathrm{I}$ presume that the following 2 points are additionally contributory and might cast some suspicions on the accuracy of the study results. 1) Al-Otaibi et al mentioned that $90.8 \%$ of the studied SCD patients had sickle cell anemia (SCA). ${ }^{1}$ However, they did not address the OSA prevalence in the patients with hemoglobin $\mathrm{S}(\mathrm{Hb} \mathrm{S})$, or $\mathrm{Hb} S$ along with other $\mathrm{Hb}$ variants that allow for $\mathrm{Hb} S$ polymerization. This point is important to be considered. For instance, an American study has found that PSG parameters differed significantly between $\mathrm{Hb}$ SS and $\mathrm{Hb}$ SC genotypes only on arterial oxyhemoglobin saturation $\left(\mathrm{SpO}_{2} ; 95.2 \pm 3.8\right.$ versus $98.0 \pm 0.8, p<0.01$ ) and percentage of sleep time below $\mathrm{SpO}_{2} 90 \%$ (T90; $8.0 \pm 22.0$ versus $0.01 \pm 0.02$, $p<0.05) .{ }^{2}$ The study concluded that children with $\mathrm{Hb}$ SS experienced more severe nocturnal oxygen desaturation than did those with $\mathrm{Hb} \mathrm{SC}{ }^{2}$ Thus, different genotypes of SCD are expected to alter the estimated PSG parameters in the Al-Otaibi et al's study. ${ }^{1}$ 2) It was not obvious in the methodology that the studied SCD patients were on treatment, particularly hydroxyurea (HU) or not. This point is important to be considered as the increase in the use of HU in the treatment of SCD has triggered studying its impact on the prevalence of OSA and nocturnal hypoxia in SCD children. A set of researchers have found that OSA was diagnosed in 38\% in the HU group and $52 \%$ in the no-HU group $(p=0.14)$. The median $\mathrm{AH}$ index was 0.9 and 1.9 events/h in the HU group and the no-HU group, respectively $(p=0.28)$. The HU group compared with the no-HU group had a significantly higher median awake $\mathrm{SaO}_{2}$ (98.6 and $96.2 \%$, respectively; $p<0.0001$ ), a significantly higher median sleep $\mathrm{SaO}_{2}$ (98.4 and $96.1 \%$, respectively; $\mathrm{P}<0.001$ ), and a significantly higher nadir $\mathrm{SaO}_{2}$ while asleep (91.4 and $85.0 \%$, respectively; $p=0.0002) .{ }^{3}$ The researchers concluded that improving nocturnal $\mathrm{SaO}_{2}$ maybe an important mechanism of action of $\mathrm{HU}$ therapy. ${ }^{3}$ Thus, HU therapy received by the SCD cohort in Al-Otaibi et al's study, if any, is expected to alter the estimated PSG parameters. Despite the aforementioned limitations, the reported OSA in Otaibi et al's study ${ }^{1}$ is alarmingly high.

Second, based on employing pediatric sleep questionnaire (PSQ), Al-Otaibi et al found a history of snoring for more than half the time during sleep in $73.8 \%$ children (of these $64.6 \%$ had an AHI $\geq 1$ ), a history of apnea during sleep in $32.8 \%(71.4 \% \mathrm{had}$ an AHI $\geq 1)$, and bed wetting in $46 \%(62.1 \%$ had an $\mathrm{AHI} \geq 1) .{ }^{1}$ It noteworthy that PSQ is an old questionnaire developed and validated by Chervin et al in $2000^{4}$ and it has a sensitivity of $81 \%$ and a specificity of $87 \%$. New questionnaires have been developed to detect patients at risk of OSA and among them, STOP-Bang questionnaire $(\mathrm{SBQ})$ has received universal attention. Systematic review and meta-analysis to determine the effectiveness of SBQ for screening patients suspected of having OSA and to predict its accuracy in determining the severity of OSA in different populations confirmed the high performance of the SBQ in the sleep clinic. ${ }^{5}$ The sensitivity was estimated to be $90 \%, 94 \%$, and $96 \%$ to detect any OSA (AHI $\geq 5$ ), moderate-tosevere OSA (AHI $\geq 15)$, and severe OSA (AHI $\geq 30$ ) respectively while the corresponding negative predictive value (NPV) was $46 \%, 75 \%$, and $90 \% .{ }^{5}$ Interestingly, the validity and reliability of the Arabic version of SBQ as a screening tool for OSA has been evaluated in KSA and it showed that it is an easy-to-administer, simple, reliable, and valid tool for the identification of OSA in the sleep disorders clinic setting. ${ }^{6}$ It exhibited a high degree of internal consistency and stability over time for the translated SBQ. The Cronbach's alpha coefficient for the 8-item tool was 0.7. Validation of the SBQ against the AHI at a cut-off of 5 revealed a sensitivity of $98 \%$ and positive and NPV of $86 \%$ and $67 \%$, respectively. ${ }^{6}$ I wonder why Otaibi et $\mathrm{al}^{1}$ referred to PSQ instead of SBQ in their study. I presume that if Otaibi et $\mathrm{al}^{1}$ employed SBQ in the methodology, the study results might be altered.

Third, the American Academy of Pediatrics recommends that all children be screened for symptoms and signs suggestive of OSA and complex cases should be referred to the specialist for further evaluation. In the view of prevailing SCD in KSA, high prevalence of OSA in Saudi SCD children, ${ }^{1}$ and elevated morbidity and health care use in children with OSA, I presume that routine screening SCD patients for OSA needs to receive particular attention by policy makers in KSA in order to decrease the morbidity, and consequently improve the quality of life in SCD patients. 
Mahmood D. Al-Mendalawi

Department of Paediatrics Al-Kindy College of Medicine University of Baghdad Baghdad, Iraq ORCID ID: orcid.org/0000-0003-2872-453X

\section{Reply from the Author}

No reply was received from the Author.

\section{References}

1. Al-Otaibi T, Al-Qwaiee M, Faraidi H, Batniji F, Al-Otaibi F, Al-Harbi A. Prevalence of obstructive sleep apnea in children with sickle cell disease at a tertiary hospital in Saudi Arabia. Saudi Med J 2017; 38: 616-620.
2. Rogers VE, Lewin DS, Winnie GB, Geiger-Brown J. Polysomnographic characteristics of a referred sample of children with sickle cell disease. J Clin Sleep Med 2010; 6: 374-381.

3. Narang I, Kadmon G, Lai D, Dhanju S, Kirby-Allen M, Odame $\mathrm{I}$, et al. Higher nocturnal and awake oxygen saturations in children with sickle cell disease receiving hydroxyurea therapy. Ann Am Thorac Soc 2015; 12: 1044-1049.

4. Chervin RD, Hedger K, Dillon JE, Pituch KJ. Pediatric sleep questionnaire (PSQ): validity and reliability of scales for sleep-disordered breathing, snoring, sleepiness, and behavioral problems. Sleep medicine 2000;1:21-32

5. Nagappa M, Liao P, Wong J, Auckley D, Ramachandran SK, Memtsoudis S, et al. Validation of the STOP-Bang Questionnaire as a Screening Tool for obstructive sleep apnea among different populations: A systematic review and metaanalysis. PLoS One 2015; 10: e0143697.

6. BaHammam AS, Al-Aqeel AM, Alhedyani AA, Al-Obaid GI, Al-Owais MM, Olaish AH. The validity and reliability of an arabic version of the STOP-bang questionnaire for identifying obstructive sleep apnea. Open Respir Med J 2015; 9: 22-29.

\section{Authorship entitlement}

Excerpts from the Uniform Requirements for Manuscripts Submitted to Biomedical Journals updated November 2003.

Available from www.icmje.org

The international Committee of Medical Journal Editors has recommended the following criteria for authorship; these criteria are still appropriate for those journals that distinguish authors from other contributors.

Authorship credit should be based on 1) substantial contributions to conception and design, or acquisition of data, or analysis and interpretation of data; 2) intellectual content; and 3) final approval of the version to be published. Authors should meet conditions 1,2 , and 3 .

Acquisition of funding, collection of data, or general supervision of the research group, alone, does not justify authorship.

An author should be prepared to explain the order in which authors are listed. 